13

\title{
Влияние толщины гидрогенизированных углеродных пленок, легированных кремнием и кислородом, на свойства их поверхности
}

\author{
(ㄱ А.С. Гренадёров, А.А. Соловьёв, К.В. Оскомов
}

Институт сильноточной электроники СО РАН, 634055 Томск, Россия

e-mail: 1711Sasha@mail.ru

Поступило в Редакцию 15 июня 2020 г.

В окончательной редакции 15 июля 2020 г.

Принято к публикации 21 июля 2020 г.

Получены гидрогенизированные углеродные пленки, легированные кремнием $(11.9 \pm 0.4$ at.\%) и кислородом $(1.7 \pm 0.1$ at.\%), толщиной $0.5-7 \mu \mathrm{m}$ на подложках из титана марки ВТ6 и кремния в плазме несамостоятельного дугового разряда с накаленным катодом. Исследована зависимость твердости, внутренних напряжений, морфологии поверхности, смачиваемости, а также поверхностного потенциала полученных пленок от их толщины. Показано, что увеличение толщины пленки способствует повышению допустимой нагрузки на материал и его твердости. При этом пленки обладают низкими внутренними напряжениями (менее $600 \mathrm{MPa})$, а краевой угол смачивания с водой составляет 75-80. Установлено, что увеличение толщины пленки приводит к повышению отрицательного поверхностного потенциала от 50 до $670 \mathrm{mV}$.

Ключевые слова: алмазоподобный углерод, $a$-C:H: $\mathrm{SiO}_{x}$-пленки, твердость, внутренние напряжения, поверхностный потенциал.

DOI: $10.21883 /$ JTF.2021.01.50287.204-20

\section{Введение}

Алмазоподобные углеродные $(a-\mathrm{C})$ и гидрогенизированные углеродные $(a-\mathrm{C}: \mathrm{H})$ пленки привлекают интерес исследователей благодаря высокой твердости, низкому коэффициенту трения, высокой износостойкости и биосовместимости [1]. Благодаря такому сочетанию свойств алмазоподобные пленки востребованы в медицине, машиностроении, авиакосмической промышленности и других областях. Однако существенным недостатком алмазоподобных пленок являются высокие внутренние напряжения сжатия (1.5-10 GPa), обусловленные значительным содержанием связей типа $s p^{3}$ и приводящие к формированию трещин в условиях высоких нагрузок [2]. Для снижения остаточных напряжений в алмазоподобных пленках и повышения их адгезии используют следующие способы: легирование пленок различными элементами (N, $\mathrm{Si}, \mathrm{F}, \mathrm{Cu}, \mathrm{Ag}, \mathrm{Mo}$, $\mathrm{SiO}_{x}$ и др.) [3-7], нанесение адгезионного подслоя [8], отжиг при высоких температурах (более $300^{\circ} \mathrm{C}$ ) [9], электронное и ионное воздействие на пленку $[10,11]$.

Легирование гидрогенизированных углеродных пленок кремнием $(a-\mathrm{C}: \mathrm{H}: \mathrm{Si})$ или $\mathrm{SiO}_{x}\left(a-\mathrm{C}: \mathrm{H}: \mathrm{SiO}_{x}\right)$ приводит к снижению внутренних напряжений, улучшает адгезию и медико-биологические свойства пленок [12]. Твердость $(H)$ пленок, содержащих кремний, при этом снижается до 10-20 GPa вследствие снижения доли $s p^{3}$ гибридизированных атомов углерода. Свойства алмазоподобных пленок, легированных кремнием или $\mathrm{SiO}_{x}$, зависят как от содержания легирующей добавки [13-15], так и условий осаждения, таких, как амплитуда импульсов напряжения смещения подложки $[16,17]$, состав и расход прекурсора $[17,18]$, плотность ионного тока на подложку [19].

Увеличение содержания кремния в $a-\mathrm{C}: \mathrm{H}: \mathrm{Si}$ пленках с 4 до 16 at.\% немного снижает твердость пленок (с 10.8 до $9.4 \mathrm{GPa})$, но заметно улучшает адгезию [13]. При этом индекс пластичности $H / E$ ( $E$ - модуль упругости $)$ и сопротивление пластической деформации $H^{3} / E^{2}$ увеличиваются с 0.08 до 0.1 и с 65 до $100 \mathrm{MPa} \mathrm{соответственно.}$ Кроме того, увеличение содержания Si в пленке приводит к улучшению их биосовместимости [14]. В [15] было показано, что увеличение содержания $\mathrm{Si}$ в $a-\mathrm{C}: \mathrm{H}: \mathrm{Si}$ пленках от 0 до 22 at.\% способствует снижению внутренних напряжений с 1.5 до $1 \mathrm{GPa}$, в то время как твердость уменьшается с 14 до $12 \mathrm{GPa}$.

В [16] показано, что трибологические свойства $a$-C:H: $\mathrm{SiO}_{x}$-пленок, полученных методом ассистированного плазмой химического газофазного осаждения (PACVD), зависят от амплитуды ВЧ напряжения смещения подложки. При оптимальном напряжении смещения $(-100 \mathrm{~V})$ наносимые пленки обладали низким коэффициентом трения (менее 0.05) и высокой адгезионной прочностью (критическая нагрузка при скретч-тесте равна $32 \mathrm{~N})$. В [17] в зависимости от напряжения смещения подложки и расхода прекурсора (гексаметилдисилоксана) твердость пленок варьировалась от 5 до $17 \mathrm{GPa}$.

В [20] было показано, что механические и трибологические свойства $a$-С:Н пленок зависят от их толщины. Пленки толщиной 1.6 и $2.4 \mu \mathrm{m}$ имели твердость 24 и $33 \mathrm{GPa}$ соответственно при близких значениях скорости износа. Это означает, что при одинаковых условиях более толстая пленка прослужит дольше. Однако зависимость свойств $a$-С:Н-пленок, легированных кремнием 
и кислородом, от толщины в настоящее время слабо изучена. В [21] были проведены измерения краевого угла смачивания $a-\mathrm{C}: \mathrm{H}: \mathrm{SiO}_{x}$-пленок толщиной от 4 до $180 \mathrm{~nm}$. Данный параметр слабо зависел от толщины пленки и находился в диапазоне от 67 до $76^{\circ}$. В работе [22] были измерены твердость $H$ и модуль упругости $E$ таких пленок толщиной от 2 до $9 \mu \mathrm{m}$. Показано, что в данном диапазоне толщин $H$ и $E$ изменяются незначительно и составляют $22-25 \mathrm{GPa}$ и 135-140 GPa соответственно.

Алмазоподобные пленки благодаря уникальному сочетанию механических, трибологических свойств и биосовместимости представляют большой интерес в медицине для использования в качестве износостойких и барьерных покрытий на металлических имплантатах. Последние обычно изготавливаются из нержавеющей стали, сплавов на основе титана и кобальта. Особую роль при взаимодействии имплантата с живыми тканями играют свойства его поверхности, важной характеристикой которых является электрическая совместимость [23]. Электрические поля в тканях регулируют миграцию [24] и жизнедеятельность клеток. Известно, что клетки крови имеют отрицательный дзета-потенциал [25], поэтому для того, чтобы клетки крови не прилипали к поверхности имплантата, его поверхность тоже должна иметь отрицательный потенциал. В случае диэлектриков поверхностный электростатический потенциал обусловлен собственными и/или приобретенными в результате внешних воздействий зарядами.

Цель настоящей работы заключалась в исследовании влияния толщины $a-\mathrm{C}: \mathrm{H}: \mathrm{SiO}_{x}$-пленок, наносимых в плазме несамостоятельного дугового разряда с накаленным катодом, на морфологию, механические свойства и электростатический потенциал модифицируемой с их помощью поверхности.

\section{1. Эксперимент и методики исследований}

В качестве подложек использовали пластины размером $15 \times 15 \mathrm{~mm}$ из титана марки ВТ-6 толщиной $0.2 \mathrm{~mm}$ ( $R_{a}$ около $\left.0.25 \mu \mathrm{m}\right)$ и $\mathrm{Si}(100)$ толщиной $440 \mu \mathrm{m}\left(R_{a}\right.$ менее $\left.0.015 \mu \mathrm{m}\right)$. В основном исследования свойств пленок проводили на подложках из сплава ВТ-6, но в некоторых случаях (например, при измерении внутренних напряжений) для удобства и повышения точности измерений использовали подложки из кремния. Для очистки подложки обрабатывались в ультразвуковой ванне, наполненной сначала изопропиловым спиртом, затем ацетоном и дистиллированной водой. В каждой жидкости очистка длилась $10 \mathrm{~min}$. После этого подложки осушались потоком сжатого воздуха. Вакууммирование рабочей камеры осуществлялось турбомолекулярным насосом до остаточного давления $10^{-2} \mathrm{~Pa}$. Блок-схема и параметры экспериментальной установки подробно описаны в нашей предыдущей работе [19].
Для уменьшения шероховатости поверхности образцы из титана марки ВТ-6 подвергались электроннопучковой обработке (ЭПО), описанной в [26]. Для этого использовался низкоэнергетический сильноточный электронный пучок с плотностью энергии $6.5 \mathrm{~J} / \mathrm{cm}^{2}$ и количеством импульсов воздействия, равным 10. После электронно-пучковой обработки шероховатость поверхности $R_{a}$ снижалась с 0.25 до $0.15 \mu \mathrm{m}$. Перед нанесением $a$-C: $\mathrm{H}: \mathrm{SiO}_{x}$-пленки подложки также подвергались обработке в плазме аргона при давлении $0.3 \mathrm{~Pa}$ в течение 10 min для удаления оксидных соединений с поверхности. В этом случае к подложкодержателю прикладывалось биполярное напряжение смещения с амплитудой отрицательного импульса $1000 \mathrm{~V}$, частотой $100 \mathrm{kHz}$ и коэффициентом заполнения $60 \%$. Ток разряда составлял $7 \pm 0.5 \mathrm{~A}$, напряжение разряда было $100 \pm 5 \mathrm{~V}$, а ток накала вольфрамового катода $45 \pm 5 \mathrm{~A}$. После этого осуществлялось нанесение $a-\mathrm{C}: \mathrm{H}: \mathrm{SiO}_{x}$-пленки в смеси аргона и паров полифенилметилсилоксана (ПФМС). Расход аргона составлял $4 \pm 0.2 l / h$, а расход ПФМС $1 \pm 0.1 \mathrm{ml} / \mathrm{h}$. При этом рабочее давление составляло $0.1 \mathrm{~Pa}$, а к подложкодержателю прикладывалось напряжение смещения с амплитудой отрицательного импульса $300 \mathrm{~V}$. Ток разряда составлял $5 \pm 0.2 \mathrm{~A}$, напряжение горения $140 \pm 5 \mathrm{~V}$, ток накала вольфрамового катода составлял $45 \pm 5$ А. Температура подложкодержателя в процессе нанесения пленки не превышала $200^{\circ} \mathrm{C}$. Скорость роста пленки составляла около $19 \pm 1 \mathrm{~nm} / \mathrm{min}$.

Для исследования поверхности полученных образцов использовался сканирующий электронный микроскоп QUANTA 200 (FEI Company, CШA). При получении изображений ускоряющее напряжение электронов составляло $30 \mathrm{kV}$, а в процессе исследования элементного состава $-10 \mathrm{kV}$. Для обработки полученных изображений использовалась программа ImageJ 1.5. Внутренние напряжения в пленке определялись по измерению кривизны кремниевого образца размером $20 \times 2 \times 0.44 \mathrm{~mm}$ до и после нанесения $a-\mathrm{C}: \mathrm{H}: \mathrm{SiO}_{x}$-пленки. Кривизна поверхности измерялась трехмерным бесконтактным профилометром Micro Measure 3D Station (STIL, Франция). Расчет внутренних напряжений производился по формуле Стоуни [27]. Краевой угол смачивания для воды определялся с использованием прибора KRÜSS Easy Drop. Производилось по 3 измерения краевого угла на каждом образце, после чего значения усреднялись. $H$ и $E$ полученных образцов измерялись с использованием прибора Nanotest 600 (Micro Materials Ltd., GB) по методике Оливера-Фарра [28]. Нагрузка на индентор изменялась от 10 до $100 \mathrm{mN}$. Производилось по 10 измерений $H$ и $E$, после чего значения усреднялись. Адгезионная прочность пленок измерялась с помощью скрэтчтестера Micro-Scratch Tester MST-S-AX-0000 (CSEM, Швейцария). Алмазная игла с радиусом острия $100 \mu \mathrm{m}$ перемещалась по поверхности пленки с постепенно увеличивающейся нагрузкой при постоянной скорости $2.45 \mathrm{~mm} / \mathrm{min}$ и скорости нагружения $3.75 \mathrm{~N} / \mathrm{min}$. Максимальная прикладываемая нагрузка составляла $15 \mathrm{~N}$, а 


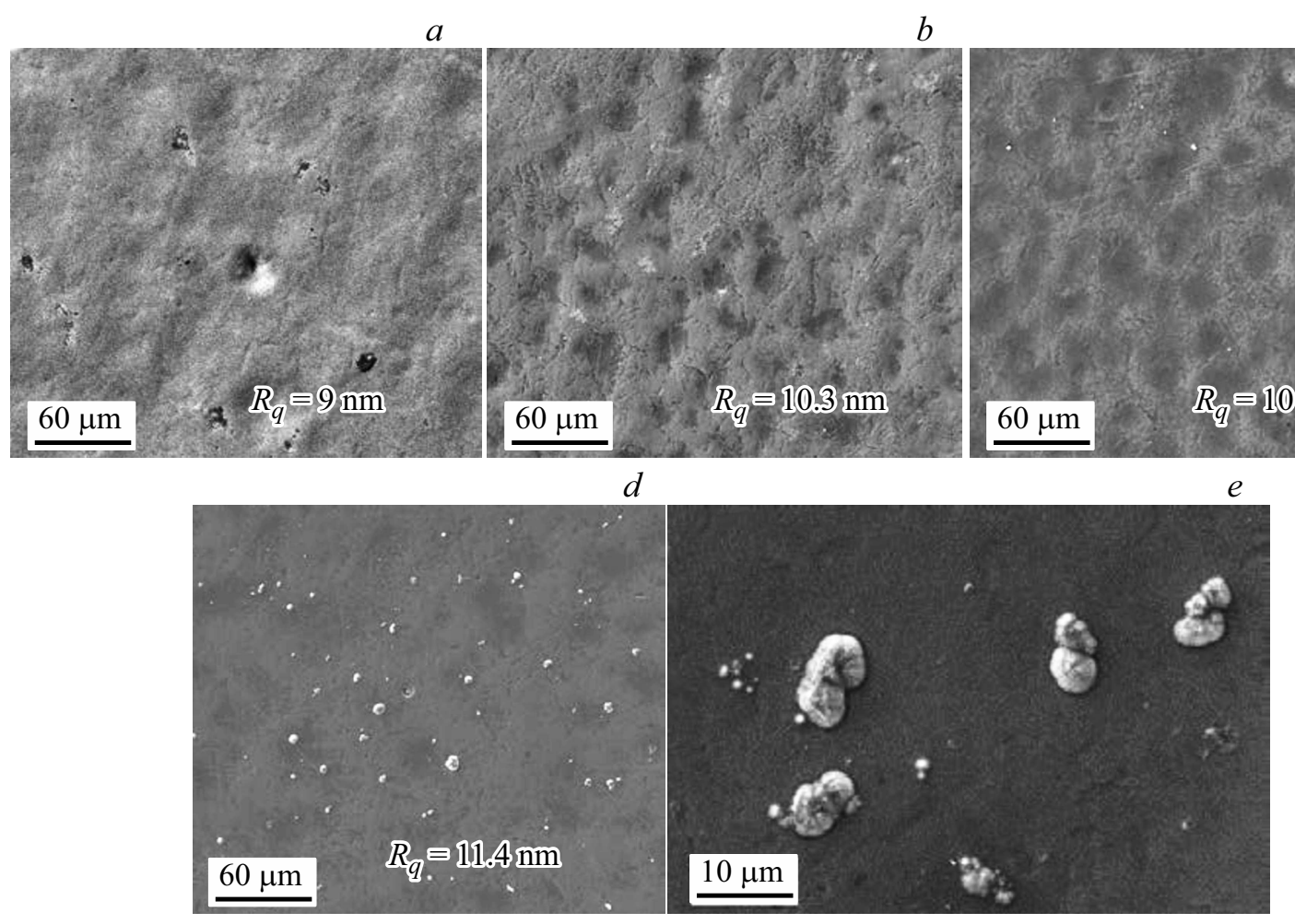

Рис. 1. СЭМ изображения поверхности $a-\mathrm{C}: \mathrm{H}: \mathrm{SiO}_{x}$ пленок различной толщины на подложках из титана марки ВТ-6: $a-$ исходный образец, $b-$ пленка толщиной $1.7 \mu \mathrm{m}, c-$ пленка толщиной $4.6 \mu \mathrm{m}, d-$ пленка толщиной $7.5 \mu \mathrm{m}, e-$ увеличенное изображение пленки толщиной $7.5 \mu \mathrm{m}$.

длина царапины $7 \mathrm{~mm}$. Для исследования шероховатости поверхности и электростатического потенциала образцов использовался атомно-силовой микроскоп Solver-HV (NT-MDT, Зеленоград, Россия) в полуконтактном режиме работы с кантилевером из $\mathrm{W}_{2} \mathrm{C}$. Обработка полученных результатов проводилась с помощью программы Gwyddion. Поверхностный потенциал определялся по методу Кельвина [29].

\section{2. Результаты и их обсуждение}

На рис. 1 представлены изображения поверхности $a-\mathrm{C}: \mathrm{H}: \mathrm{SiO}_{x}$-пленки, нанесенной на образцы из титана марки ВТ-6. Известно, что аморфные алмазоподобные покрытия обладают низкой шероховатостью поверхности $(0.2-2 \mathrm{~nm})$ [30]. Поэтому морфология поверхности образцов с пленкой во многом определяется шероховатостью подложки. При малых толщинах морфология поверхности пленки повторяет рельеф поверхности подложки, а увеличение толщины аморфной пленки должно способствовать ее сглаживанию. На рис. 1, $a$ представлено изображение поверхности образца титана после электронно-пучковой обработки (ЭПО). ЭПО изменяет структуру поверхностного слоя благодаря процессу динамической рекристаллизации, инициированному сверхвысокими скоростями нагрева и охлаждения. На поверхности образца могут присутствовать впадины или микрократеры, количество которых можно минимизировать путем подбора условий электронно-пучковой обработки [31]. Из рис. $1, b$ видно, что при толщине $a$-C : $\mathrm{H}: \mathrm{SiO}_{x}$-пленки $1.7 \mu \mathrm{m}$ на поверхности образца присутствуют впадины, которые остаются даже после ЭПО. При толщине пленки $4.6 \mu \mathrm{m}$ впадины на поверхности образца становятся менее выраженными (рис. 1,c), а увеличение толщины пленки до $7.5 \mu \mathrm{m}$ приводит к практически полному их исчезновению (рис. $1, d)$.

Согласно энергодисперсионному анализу, в пленках содержится $83 \pm 1$ at.\% углерода, $11.9 \pm 0.4$ at.\%. кремния, $1.7 \pm 0.1$ at.\% кислорода и $3.2 \pm 0.3$ at.\% аргона. Наличие аргона в пленке можно объяснить бомбардировкой ее ионами аргона в процессе роста. На поверхности пленки толщиной $7.5 \mu \mathrm{m}$ обнаружены частицы сложной формы размером до $9 \mu \mathrm{m}$ (рис. 1,e). Энергодисперсионный анализ показал, что данные частицы содержат около 32 at.\% кремния, что значительно превышает его содержание в пленке. Более детальные исследования структуры формируемых $a-\mathrm{C}: \mathrm{H}: \mathrm{SiO}_{x}$-пленок с помощью рентгеновской фотоэлектронной, рамановской и инфракрасной спектроскопии представлены в наших предыдущих работах [31,32].

Согласно результатам атомно-силовой микроскопии, среднеквадратичная шероховатость поверхности $R_{q}$ полученных образцов составляет около $10 \pm 1 \mathrm{~nm}$ на участках размером $5 \times 5 \mu \mathrm{m}$. 


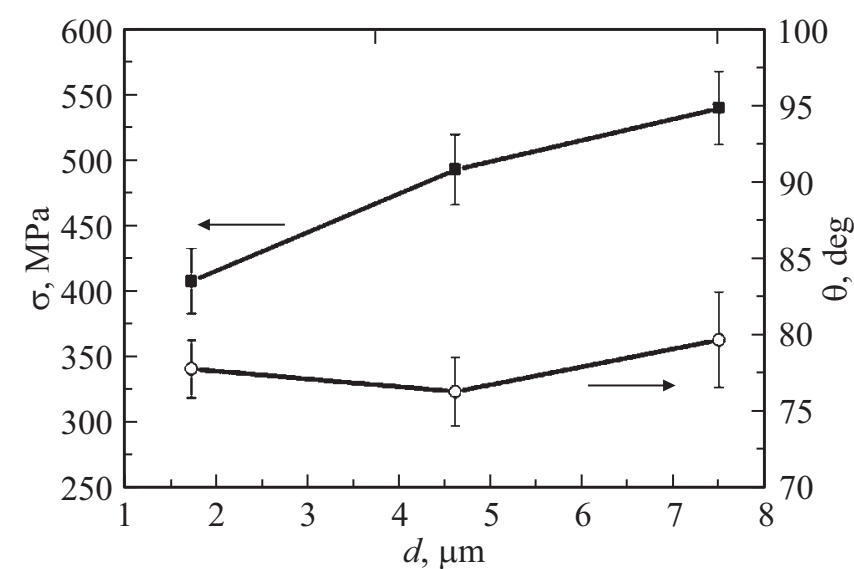

Рис. 2. Зависимость внутренних напряжений $\sigma$ и краевого угла смачивания $\theta$ от толщины $a-\mathrm{C}: \mathrm{H}: \mathrm{SiO}_{x}$-пленки.

На рис. 2 представлена зависимость внутренних напряжений $\sigma$ и краевого угла смачивания $\theta$ от толщины пленки. Установлено, что $a-\mathrm{C}: \mathrm{H}: \mathrm{SiO}_{x}$-пленки характеризуются сжимающими внутренними напряжениями. С увеличением толщины пленки с 1.7 до $7.5 \mu \mathrm{m}$ внутренние напряжения увеличиваются с 410 до $530 \mathrm{MPa}$ Несмотря на это, внутренние напряжения полученных пленок значительно уступают по величине внутренним напряжениям алмазоподобных пленок. Даже $a-\mathrm{C}: \mathrm{H}: \mathrm{SiO}_{x}$-пленки толщиной $1 \mu \mathrm{m}$, полученные Батори с соавторами [17], характеризовались большими внутренними напряжениями $(0.5-1.4 \mathrm{GPa}$ в зависимости от напряжения смещения подложки и расхода гексаметилдисилоксана).

Явной зависимости краевого угла смачивания от толщины $a$-C:H: $\mathrm{SiO}_{x}$-пленок не наблюдается (рис. 2). Для исследуемых пленок краевой угол смачивания находился в диапазоне от 74 до $79^{\circ}$. Близкие значения контактного угла $\left(75-78^{\circ}\right)$ наблюдались для $a-\mathrm{C}: \mathrm{H}: \mathrm{SiO}_{x}$-пленок, полученных в работе [33]. Отсутствие зависимости краевого угла смачивания от толщины пленок вполне ожидаемо, поскольку смачиваемость поверхности определяется химическим составом пленки и наличием на ее поверхности полярных функциональных групп, что не зависит от толщины пленки.

На рис. 3 представлены зависимости твердости от нагрузки на индентор в диапазоне $10-100 \mathrm{mN}$ для образца из титана марки ВТ-6 и $a-\mathrm{C}: \mathrm{H}: \mathrm{SiO}_{x}$-пленок различной толщины, нанесенных на него. Для образца без пленки увеличение нагрузки от 10 до $100 \mathrm{mN}$ приводит к снижению с твердости с 4.5 до $3 \mathrm{GPa}$ (рис. 3, кривая 1). Нанесение $a$-C:H: $\mathrm{SiO}_{x}$-пленки толщиной $1.7 \mu \mathrm{m}$ приводит к трехкратному увеличению твердости поверхности (до $14.3 \mathrm{GPa}$ ) при нагрузке $10 \mathrm{mN}$. В этом случае глубина проникновения индентора составляет $162 \mathrm{~nm}$. При повышении нагрузки до $100 \mathrm{mN}$ твердость снижается до $4.8 \mathrm{GPa}$, что объясняется влиянием подложки с меньшей твердостью. Известно, что для измерения реального значения твердости пленки глубина проникновения индентора не должна превышать 10\% от толщины пленки [34]. Поскольку при нагрузке 40 и $100 \mathrm{mN}$ глубина проникновения индентора равна 550 и $1100 \mathrm{~nm}$ соответственно, для пленки толщиной $1.7 \mu \mathrm{m}$ корректно рассматривать значения твердости только при нагрузке $10 \mathrm{mN}$. У пленки толщиной $4.6 \mu \mathrm{m}$ при нагрузке $10 \mathrm{mN}$ твердость составляет $15.6 \mathrm{GPa}$, а увеличение нагрузки до $100 \mathrm{mN}$ не приводит к значительному снижению твердости. Это говорит о том, что влияние подложки на измеренные значения твердости уменьшается. Глубина проникновения индентора при нагрузке $100 \mathrm{mN}$ составляет $550 \mathrm{~nm}$. При нанесении $a-\mathrm{C}: \mathrm{H}: \mathrm{SiO}_{x}$-пленки толщиной $7.5 \mu \mathrm{m}$ твердость поверхности образцов в исследуемом диапазоне нагрузок даже немного увеличивается (рис. 3, кривая 4). При нагрузке $40 \mathrm{mN}$ твердость составила $19.2 \mathrm{GPa}$ (глубина проникновения индентора при этом была равна $342 \mathrm{~nm}$ ). По-видимому, даже если глубина проникновения индентора не превышает 10\% от толщины пленки, то подложка все равно оказывает влияние на результат измерения твердости.

На рис. 4 представлены результаты исследования адгезии $a-\mathrm{C}: \mathrm{H}: \mathrm{SiO}_{x}$-пленок методом скретч-теста, в частности, сигналы датчика акустической эмиссии и изображения участков царапины при нескольких нагрузках на индентор. Согласно данным акустической эмиссии, наибольшая критическая нагрузка, при которой происходит разрушение покрытия, соответствует пленке c наименьшей толщиной $(1.7 \mu \mathrm{m})$. Для этой пленки критическая нагрузка составляет 13 N. При увеличении толщины пленки до 4.6 и $7.5 \mu \mathrm{m}$ критическая нагрузка снижается до $9 \mathrm{~N}$.

Потенциал электростатического поля на поверхности $a-\mathrm{C}: \mathrm{H}: \mathrm{SiO}_{x}$-пленок измерялся двухпроходным методом зонда Кельвина с помощью атомно-силового микроскопа. В первом проходе определяется рельеф поверхности образца с использованием полуконтактного метода. На втором проходе этот рельеф отслеживается при про-

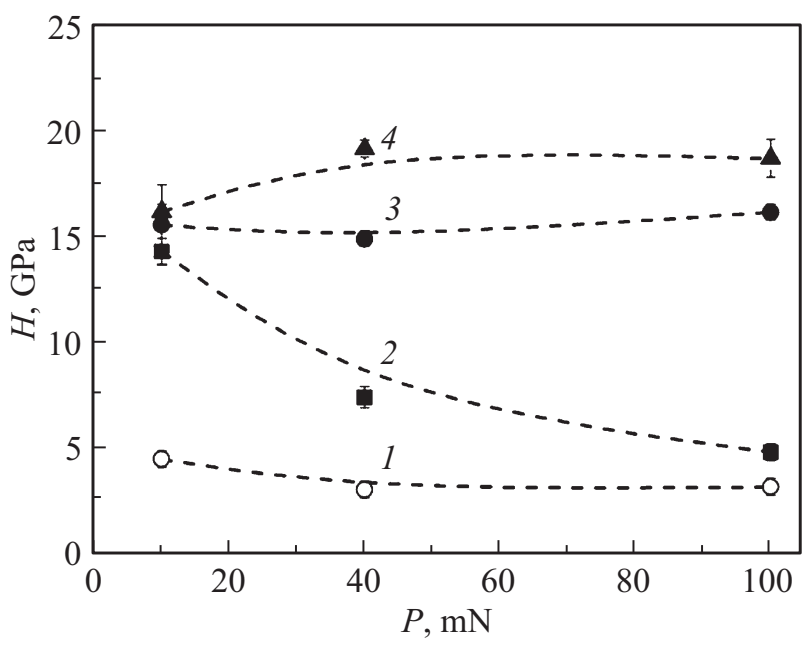

Рис. 3. Зависимости твердости $H$ от нагрузки на индентор $P$-образца из титана марки ВТ-6 (1) и $a$-C:H: $\mathrm{SiO}_{x}$-пленки толщиной 1.7 (2), 4.6 (3) и $7.5 \mu \mathrm{m}(4)$. 

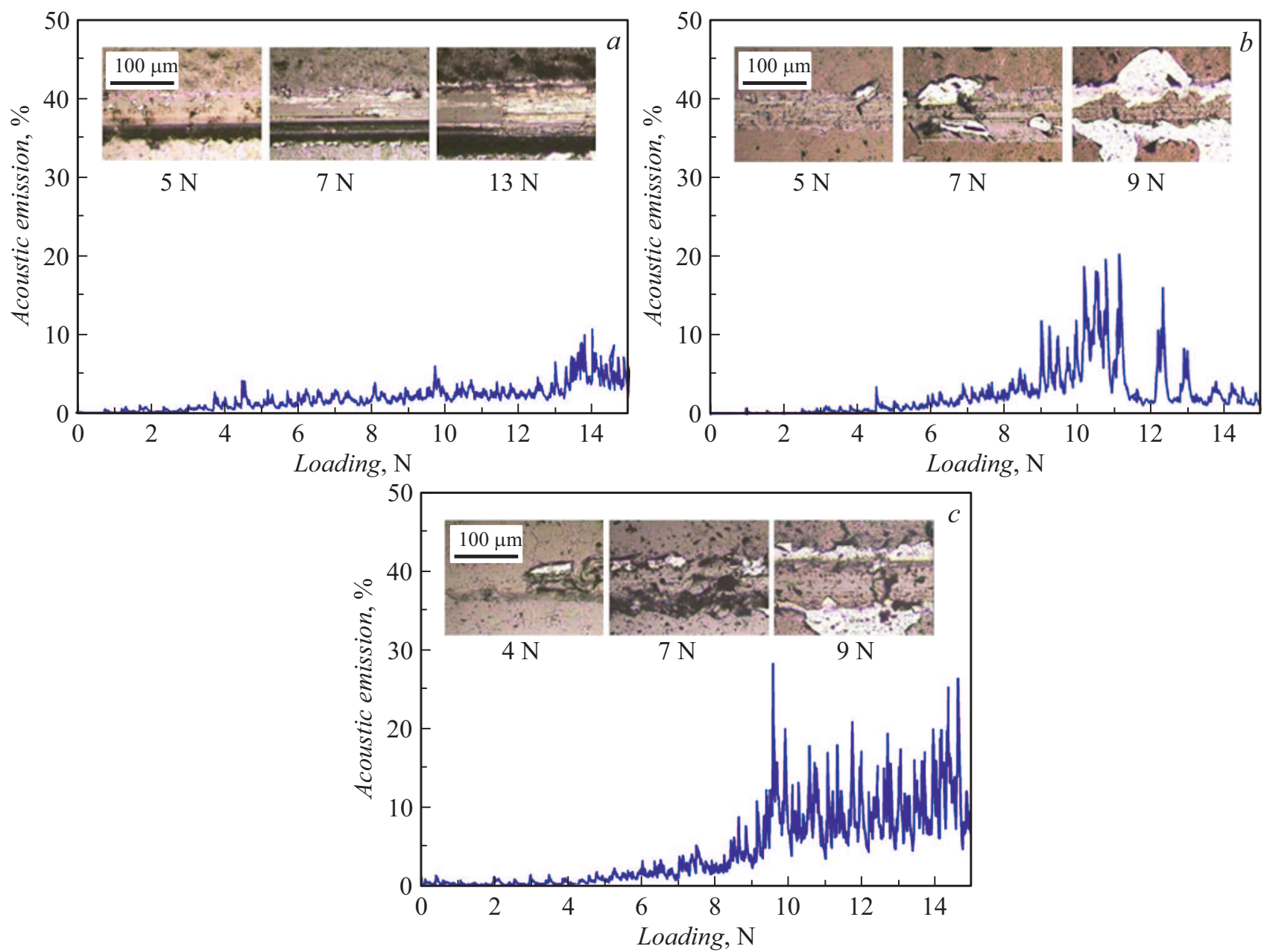

Рис. 4. Сигналы датчика акустической эмиссии и снимки царапин при скретч-тесте $a$-C: $\mathrm{H}: \mathrm{SiO}_{x}$-пленок толщиной $1.7(a), 4.6(b)$ и $7.5 \mu \mathrm{m}(c)$.

Значения среднего поверхностного потенциала $a$-C: $\mathrm{H}: \mathrm{SiO}_{x}$ пленки в зависимости от ее толщины

\begin{tabular}{c|c|c}
\hline \multirow{2}{*}{ Толщина пленки, $\mu \mathrm{m}$} & \multicolumn{2}{|c}{ Поверхностный потенциал, $\mathrm{mV}$} \\
\cline { 2 - 3 } & Si-подложка & $\begin{array}{c}\text { Подложка из титана } \\
\text { марки ВТ-6 }\end{array}$ \\
\hline 0.5 & -48.2 & -65.9 \\
\hline 1 & -280 & -210.9 \\
\hline 4 & -520.1 & - \\
\hline 7 & -676.7 & -
\end{tabular}

хождении над образцом на некоторой высоте для определения поверхностного электрического потенциала. Обнаружено, что поверхностный потенциал $a$-C: $\mathrm{H}: \mathrm{SiO}_{x}$ пленок, нанесенных на подложки из кремния и сплава ВТ-6, имеет отрицательные значения (см. таблицу). Причем увеличение толщины пленки с 0.5 до $7 \mu \mathrm{m}$ на $\mathrm{Si}$-подложках приводит к увеличению среднего значения поверхностного потенциала от -50 до $-670 \mathrm{mV}$. На подложках из сплава ВТ-6 потенциал имеет сравнимые значения и также обнаруживает тенденцию к росту с увеличением толщины пленки.

Согласно результатам энергодисперсионного анализа, элементный состав пленки при увеличении толщины не изменяется. Соответственно диэлектрическая проницаемость пленки одинакова для всех толщин. Это значит, что на изменение поверхностного потенциала оказывает влияние емкость диэлектрика, которая обратно пропорциональна толщине исследуемой $a-\mathrm{C}: \mathrm{H}: \mathrm{SiO}_{x}$-пленки.

\section{Заключение}

Исследовано влияние толщины гидрогенизированных углеродных пленок, легированных кремнием $(11.9 \pm 0.4$ at.\%) и кислородом $(1.7 \pm 0.1$ at.\%), полученных в плазме несамостоятельного дугового разряда с накаленным катодом, на морфологию их поверхности, твердость, внутренние напряжения, адгезию и поверхностный электрический потенциал. Показано, что 
увеличение толщины $a$-C: $\mathrm{H}: \mathrm{SiO}_{x}$-пленки в диапазоне $1.7-7.5 \mu \mathrm{m}$ приводит к сглаживанию рельефа поверхности подложек из титана марки ВТ-6. Несмотря на то, что увеличение толщины пленок приводит к увеличению внутренних сжимающих напряжений с 400 до $550 \mathrm{MPa}$, последние имеют значения значительно меньшие, чем у нелегированных алмазоподобных покрытий. Нанесение $a$-C: $\mathrm{H}: \mathrm{SiO}_{x}$-пленки на подложки из титана марки BT-6 приводит к улучшению их твердости, а увеличение толщины пленки повышает допустимую нагрузку на материал, что важно для применения таких пленок в качестве защитных или износостойких. Показано, что увеличение толщины $a$-C:H: $\mathrm{SiO}_{x}$-пленки приводит к увеличению отрицательного поверхностного потенциала от 50 до $670 \mathrm{mV}$, что важно для применения этих пленок при производстве медицинских изделий и имплантатов, контактирующих с кровью.

\section{Благодарности}

Авторы выражают благодарность Томскому региональному научному центру коллективного пользования ТНЦ СО РАН за предоставленный наноиндентор NanoTest 600.

\section{Финансирование работы}

Работа выполнена при финансовой поддержке гранта президента Российской Федерации, проект МК-1234.2020.8. Измерения поверхностного электрического потенциала проводили в рамках гранта РНФ № 19-19-00186.

\section{Конфликт интересов}

Авторы заявляют, что у них нет конфликта интересов.

\section{Список литературы}

[1] Xiaokai An, Zhongzhen Wu, Liangliang Liu, Tielei Shao, Shu Xiao, Suihan Cui, Hai Lin, Ricky K.Y. Fu, Xiubo Tian, Paul K. Chu, Feng Pan. Surf. Coat. Tech., 365, 152 (2019). DOI: 10.1016/j.surfcoat.2018.08.099

[2] C.W. Zou, H.J. Wang, L. Feng, S.W. Xue. Appl. Surf. Sci., 286, 137 (2013). DOI: 10.1016/j.apsusc.2013.09.036

[3] D.C. Sutton, G. Limbert, D. Stewart, R.J.K. Wood. Friction, 1 (3), 210 (2013). DOI: 10.1007/s40544-013-0023-1

[4] R. Paul, S. Bhattacharyya, R. Bhar, A. Pal. Appl. Surf. Sci., 257, 10451 (2011). DOI: 10.1016/j.apsusc.2011.06.144

[5] W. Yue, X. Gao, C. Wang, Z. Fu, X. Yu, J. Liu. Mater. Lett., 73, 202 (2012). DOI: 10.1016/j.matlet.2012.01.044

[6] Xiaowei Li, Pelling Ke, Aiying Wang. AIP Advanced, 5, 017111-1 (2015). DOI: 10.1063/1.4905788

[7] Heon Woong Choi, Reinhold H. Dauskardt, Seung-Cheol Lee, Kwang-Ryeol Lee, Kyu Hwan Oh. Diam. Relat. Mater., 17, 252 (2008). DOI: 10.1016/j.diamond.2007.12.034

[8] K.-R. Lee, K.Y. Eun, I. Kim, J. Kim. Thin Solid Films, 377378, 261 (2000). DOI: 10.1016/S0040-6090(00)01429-2
[9] Abdul Wasy Zia, Zhifeng Zhou, Po Wan Shum, Lawrence Kwok Yan Li. Surf. Coat. Tech., 320, 118 (2017). DOI: 10.1016/j.surfcoat.2017.01.089

[10] P.A. Karaseov, O.A. Podsvirov, K.V. Karabeshkin, A.Ya. Vinogradov, A. Azarov, A.I. Titov, A.S. Smirnov. Nucl. Inst. Meth. Phys. Res. B, 268, 3107 (2010). DOI: 10.1016/j.nimb.2010.05.063

[11] M. Shiureviciute, J. Laurikaitiene, D. Adliene, L. Augulis, Z. Rutkuniene, A. Jotautis. Vacuum, 83, s159 (2009). DOI: $10.1016 /$ j.vacuum.2009.01.052

[12] K. Koshigan, F. Mangolini, J.B. McClimon, B. Vacher, S. Bec, R.W. Carpick, J. Fontaine. Carbon, 93, 851 (2015). DOI: 10.1016/j.carbon.2015.06.004

[13] D. Bociaga, A. Sobczyk-Guzenda, W. Szymanski, A. Jedrzejczak, A. Jastrzebska, A. Olejnik, K. Jastrzebski. Appl. Surf. Sci., 417, 23 (2017). DOI: $10.1016 /$ j.apsusc.2017.03.223

[14] D. Bociaga, M. Kaminska, A. Sobczyk-Guzenda, K. Jastrzebska, L. Swiatek, A. Olejnik. Diam. Relat. Mater., 67, 41 (2016). DOI: 10.1016/j.diamond.2016.01.025

[15] A. Bendavid, P.J. Martin, C. Comte, E.W. Preston, A.J. Haq, F.S. Magdon Ismail, R.K. Singh. Diam. Relat. Mater., 16, 1616 (2007). DOI: 10.1016/j.diamond.2007.02.006

[16] N. Kumar, S.A. Barve, S.S. Chopade, K. Rajib, N. Chand, D. Sitaram, A.K. Tyagi, D.S. Patil. Trib. Inter., 84, 124 (2015). DOI: 10.1016/j.triboint.2014.12.001

[17] D. Batory, A. Jedrzejczak, W. Szymanski, P. Niedzielski, M. Fijalkowski, P. Louda, I. Kotela, M. Hromadka, J. Musil. Thin Solid Films, 590, 299 (2015). DOI: $10.1016 /$ j.tsf.2015.08.017

[18] A.S. Grenadyorov, K.V. Oskomov, N.F. Kovsharov, A.A. Solovyev. J. Phys.: Conf. Ser., 1115, 042046 (2018). DOI: $10.1088 / 1742-6596 / 1115 / 4 / 042046$

[19] A.S. Grenadyorov, A.A. Solovyev, K.V. Oskomov, V.O. Oskirko. J. Vac. Sci. Tech. A, 37 (6), 061512 (2019). DOI: $10.1116 / 1.5118852$

[20] F.F. Conde, J.A.Á. Diaz, G.F. da Silva, A.P. Tschiptschin. Mater. Res., 22 (2), e20180499 (2019). DOI: 10.1590/1980-5373-mr-2018-0499

[21] S. Meskinis, S. Tamulevicius, V. Kopustinskas, M. Andrulevičius, A. Guobienè, R. Gudaitis, I. Liutvinienė. Thin Solid Films, 515 (19), 7615 (2007). DOI: $10.1016 /$ j.tsf.2006.11.089

[22] E.V. Zavedeev, O.S. Zilova, A.D. Barinov, M.L. Shupegin, N.R. Arutyunyan, B. Jaeggi, B. Neuenschwander, S.M. Pimenov. Diam. Relat. Mater., 74, 45 (2017). DOI: 10.1016/j.diamond.2017.02.003

[23] И.А. Хлусов, В.Ф. Пичугин, Э.А. Гостищев, Ю.П. Шаркеев, Р.А. Сурменев, М.А. Сурменева, Е.В. Легостаева, М.В. Чайкина, М.В. Дворниченко, Н.С. Морозова. Бюллетень сибирской медицины, 10 (3), 72 (2011). [I.A. Khlusov, V.F. Pichugin, E.A. Gostischev, Y.P. Sharkeyev, R.A. Surmenev, M.A. Surmeneva, Y.V. Legostayeva, M.V. Chaikina, M.V. Dvornichenko, N.S. Morozova. Bull. Siber. Med., 10 (3), 72 (2011). DOI: $10.20538 / 1682-0363-2011-3-72-81]$

[24] M. Zhao, B. Song, J. Pu, T. Wada, B. Reid, G. Tai, F. Wang, A. Guo, P. Walczysko, Yu Gu, T. Sasaki, A. Suzuki, J.V. Forrester, H.R. Bourne, P. Devreotes, C. Mccaig, J.M. Penninger. Nature, 442 (7101), 457 (2006). DOI: $10.1038 /$ nature 04925

[25] О.В. Бондарь, Д.В. Сайфуллина, И.И. Мавлютова, Т.И. Абдуллин. Acta Naturae, 4 (12), 80 (2012). 
[26] В.П. Ротштейн, Р. Гюнцель, А.Б. Марков, Д.И. Проскуровский, М.Т. Фам, Э. Рихтер, В.А. Шулов. Физика и химия обработки материалов, 1, 62 (2006).

[27] J.B. Cai, X.L. Wang, W.Q. Bai, X.Y. Zhao, T.Q. Wang, J.P. Tu. Applied Surface Science, 279, 450 (2013). DOI: 10.1016/j.apsusc.2013.04.136

[28] W.C. Oliver, G.M. Pharr. J. Mater. Res., 19(1), 3 (2004). DOI: $10.1557 / \mathrm{jmr} .2004 .19 .1 .3$

[29] V.A. Novikov, D.V. Grigoryev, A.V. Voitsekhovskii, S.A. Dvoretsky, N.N. Mikhailov. J. Surf. Inv.: X-ray, Synch. Neutr. Tech., 10 (5), 1096 (2016). DOI: $10.1134 / \mathrm{S} 1027451016050372$

[30] X.L. Peng, Z.H. Barber, T.W. Clyne. Surf. Coat. Technol., 138, 23 (2001). DOI: 10.1016/S0257-8972(00)01139-7

[31] A.S. Grenadyorov, A.A. Solovyev, K.V. Oskomov, S.A. Onischenko, A.M. Chernyavskiy, M.O. Zhulkov, V.V. Kaichev. Surf. Coat. Tech., 381, 125113 (2020). DOI: 10.1016/j.surfcoat.2019.125113

[32] A.S. Grenadyorov, A.A. Solovyev, K.V. Oskomov, V.S. Sypchenko. Surf. Coat. Tech., 349, 547 (2018). DOI: 10.1016/j.surfcoat.2018.06.019

[33] A.A. Ogwu, T.I.T. Okpalugo, J.A.D. McLaughlin. AIP ADVANCES, 2 (3), 032128 (2012). DOI: $10.1063 / 1.4742852$

[34] А.Р. Шугуров, А.В. Панин, К.В. Оскомов. ФТТ, 50 (6), 1007 (2008). [A.R. Shugurov, A.V. Panin, K.V. Oskomov. Physics Solid State, 50 (6), 1050 (2008).

DOI: $10.1134 / \mathrm{S} 1063783408060097]$ 